\title{
DSC Cure Studies of High Performance Epoxy Resins II. The Reaction with HPT Curing Agent from Isothermal Experiment
}

\author{
Jyong Sup SHIM, Weon LEE, and Jyongsik JANG* \\ Department of Chemical Technology, Seoul National University, \\ Sinlimdong Kwanakgu, Seoul 151-741, Korea \\ * Polymer Composites Laboratory, Korea Institute of Science \& Technology, \\ P.O. Box 131, Cheongryang, Seoul 131, Korea
}

(Received September 14, 1990)

\begin{abstract}
Isothermal cure kinetics of new epoxy resin/TGMAP curing agent system were studied by differential scanning calorimetry. Based on the assumption with the overall reaction order of 2, kinetic parameters were determined from an autocatalytic kinetic model and the model with modified manipulation. Compared to previous calculation of kinetic parameters, the model with modified manipulation has good fitting with experimental results. An increase in reaction rate was observed at higher cure temperature. For a given formulation, cure temperature increases with increasing the maximum cure rate and decreasing the time required to reach the maximum peak. The conversion at the maximum cure rate is independent of the cure temperature. Studies on cure temperature were also undertaken as a function of reaction rate constant.

KEY WORDS Epoxy Resin / Epoxy Curing Agent / Isothermal Scan / Epoxy Cure / Cure Rate / Cure Time / Degree of Conversion / Kinetic Parameter / Activation Energy /
\end{abstract}

In the aircraft/aerospace industry, tetraglycidyl-4,4'-diaminodiphenylmethane (TGDDM)/diaminodiphenyl sulfone (DDS) system, which meets the performance requirements for advanced composites, is currently used for many applications along with good processibility. ${ }^{1-10}$ Based on the industry's experience, TGDDM/DDS systems have poor hot/wet performance properties and have limited to apply for environmental resistant materials. ${ }^{11-13}$

Recently, new epoxy resins, $N, N, N^{\prime}, N^{\prime}-$ tetraglycidyl- $\alpha, \alpha^{\prime}$-bis(4-aminophenyl)- $p$-diisopropylbenzene (EPON HPT Resin 1071, abbreviated to TGAP), and $N, N, N^{\prime}, N^{\prime}$-tetraglycidyl- $\alpha, \alpha^{\prime}$-bis(3,5-dimethyl-4-aminophenyl)p-diisopropylbenzene (EPON HPT Resin 1072, abbreviated to TGMAP), have been developed by Shell Chemical Company as shown in Part I. New curing agent, which is a less polar amine than DDS, is $\alpha, \alpha^{\prime}$-bis(3,5-dimethyl-4-aminophenyl)-p-diisopropylbenzene (EPON HPT Curing Agent 1062, abbreviated to DAP). These epoxy resins have high glass transition temperature, low water absorption and good hot/wet properties. ${ }^{14-17}$

The cure kinetics of epoxy resins have been studied by means of differential scanning calorimetry (DSC). ${ }^{18-20}$ Dyamic and isothermal methods are largely used for the study of epoxy cure. ${ }^{21-27}$ However it has been reported that the kinetic results obtained from isothermal method would be most consistent and reliable. ${ }^{23}$

Cure studies for new epoxy resins are essential for the understanding of matrix properties in high performance composites. Numerous studies of cure kinetics mostly have been focussed on the TGDDM/DDS system. ${ }^{2-10}$ In part $I$, we discussed the cure 
kinetics of TGAP/DDP system. In this paper, DAP curing agent was used for the cure reaction with TGAP resin.

The present study is concerned with not only the analysis of cure kinetics but also an accurate estimation procedure for the determination of the kinetic parameters by means of isothermal differential scanning calorimetry (DSC) scans.

\section{EXPERIMENTAL}

\section{Materials}

The epoxy resin used in this study was EPON HPT 1071 described in Part I. The curing agent (EPON HPT 1062) was $\alpha, \alpha^{\prime}$-bis(3,5-dimethyl4-aminophenyl)-p-diisopropyl benzene, also supplied by Shell Chemical Company. The structures of EPON HPT 1071 (TGAP resin) and EPON HPT 1062 (DAP curing agent) were shown in Figure 1. Physical properties of epoxy resin and curing agent used in this study were illustrated in Table I. Three sorts of the epoxy compounds, $\mathrm{HH} 1, \mathrm{HH} 2$ and $\mathrm{HH} 3$, were prepared by changing the molar ratio of diamine (DAP)/epoxide (TGAP), $\gamma$. The values of $\gamma$ of $\mathrm{HH} 1, \mathrm{HH} 2$ and $\mathrm{HH} 3$ were $1.0,0.71$ and 0.54 , respectively. The mixture was prepared by dissolving the resin and the curing agent in methylene chloride, followed by evaporating the solvent in vacuum oven at room temperature.

\section{Methods}

The calorimetric measurement was conducted using a Perkin-Elmer 4 differential scanning calorimeter with microprocess controller. The temperature and power calibration of the DSC were optimized for the temperature of $20^{\circ} \mathrm{C}-300^{\circ} \mathrm{C}$ by using high purity indium as the DSC standard calibration.

From the dynamic experiment of HPT 1071/HPT 1062 system, it has been obtained that heat of isothermal cure at $210^{\circ} \mathrm{C}$ was less than $70 \%$ heat of dynamic cure of $\mathrm{HH} 2$ and HH3. ${ }^{28}$ This fact indicates that isothermal cure condition does not approach the second
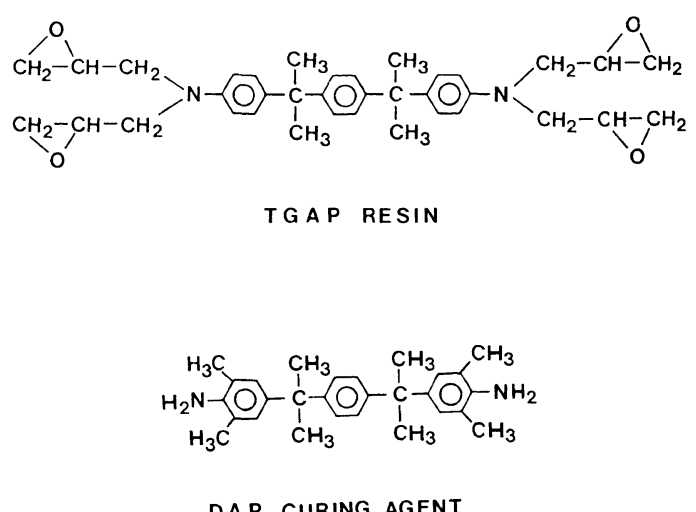

Figure 1. The structure of TGAP resin and DAP curing agent.

Table I. Physical properties of TGAP resin

$\begin{array}{lc}\text { Physical form } & \text { Dark colored solid } \\ \text { Epoxy equivalent weight } & 150-170 \\ \text { Melting point } & 122^{\circ} \mathrm{C} \\ \text { (ASTM D3461, Mettler, } 1^{\circ} \mathrm{C} / \mathrm{min} \text { ) } \\ \text { Melt viscosity at } 110^{\circ} \mathrm{C} & 18-22 \text { poise (Brooknield) } \\ T_{\mathrm{g}} & 23^{\circ} \mathrm{C} \text { (DSC) }\end{array}$

exotherm obtained from dynamic experiment of $\mathrm{HH} 2$ and $\mathrm{HH} 3$. Therefore, isothermal cure study has been carried out for $\mathrm{HH} 1$, which shows single exotherm peak from the dynamic experiment.

\section{RESULTS AND DISCUSSION}

Isothermal DSC thermograms of TGAP resin/DAP curing agent system are shown in Figure 2. The cure rate of epoxy resin passes through a maximum point and then decreases as a function of cure time. Furthermore, the cure rate at peak $\left(\alpha_{\mathrm{p}}\right)$ increases with increasing in the cure temperature. These facts indicate that cure reaction of TGAP resin/DAP curing agent system follows the autocatalytic reaction as shown in eq 3 and 4 in Part I.

The maximum isothermal cure rate $\left(\dot{\alpha}_{\mathrm{p}}\right)$ and the cure time required to reach maximum peak $\left(t_{\mathrm{p}}\right)$ are plotted against cure temperature as shown in Figures 3 and 4, respectively. Higher 


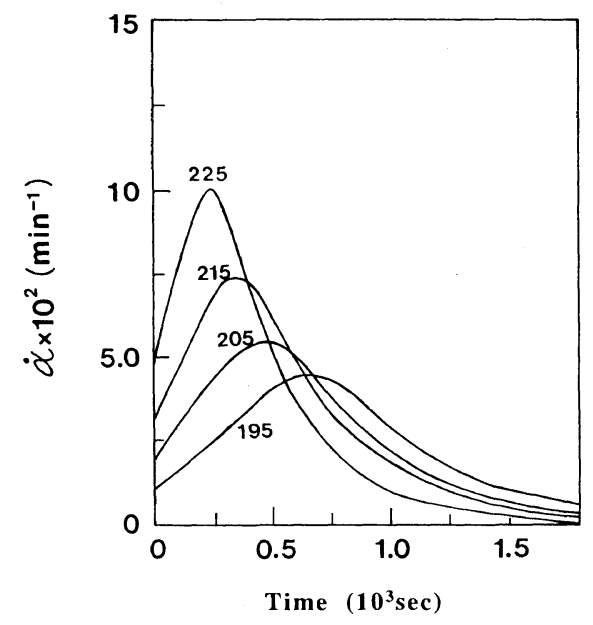

Figure 2. Cure rate as a function of cure time. The numbers in the figure indicate cure temperatures.

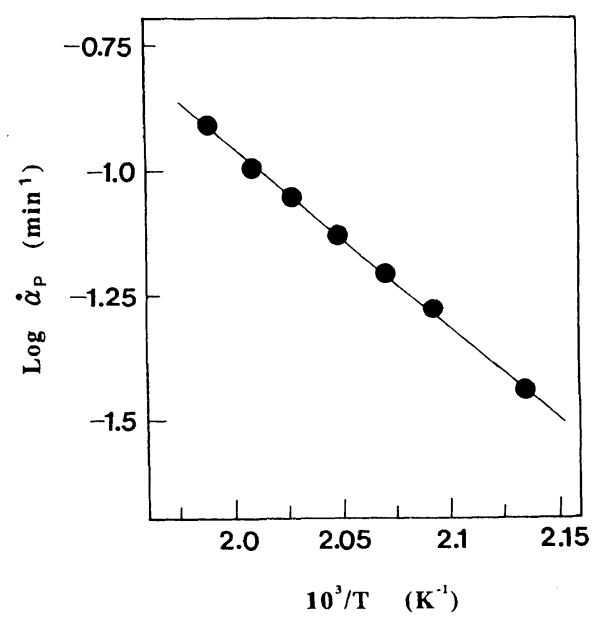

Figure 3. Cure rate at peak as a function of reciprocal cure temperature.

cure temperature increases the maximum cure rate, but decreases the time required at the maximum peak. The conversion at the maximum cure rate $\left(\alpha_{p}\right)$ was independent of the cure temperature, as shown in Figure 5. Maximum cure rate observed between 0.32 and 0.35 conversion. These values are in fairly good agreement with the literature value. ${ }^{9}$

Ryan et al. studied the cure kinetics of epoxy cure using a rapid technique for kinetic parameter estimation. ${ }^{27}$ They assumed that

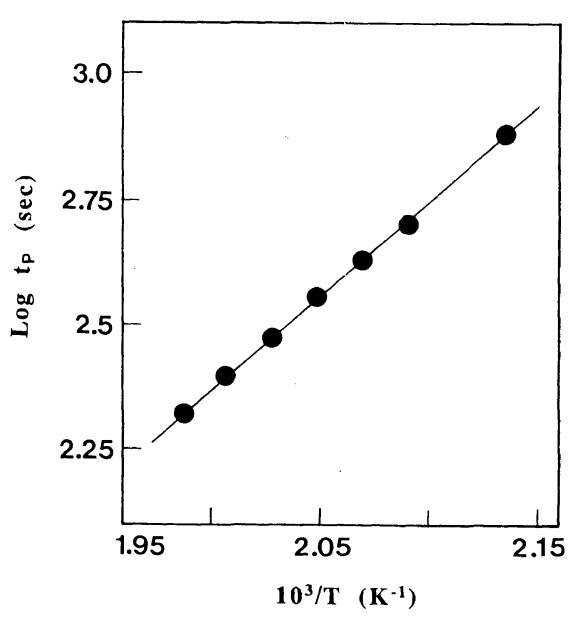

Figure 4. Logarithm cure time to peak as a function of reciprocal cure temperature.

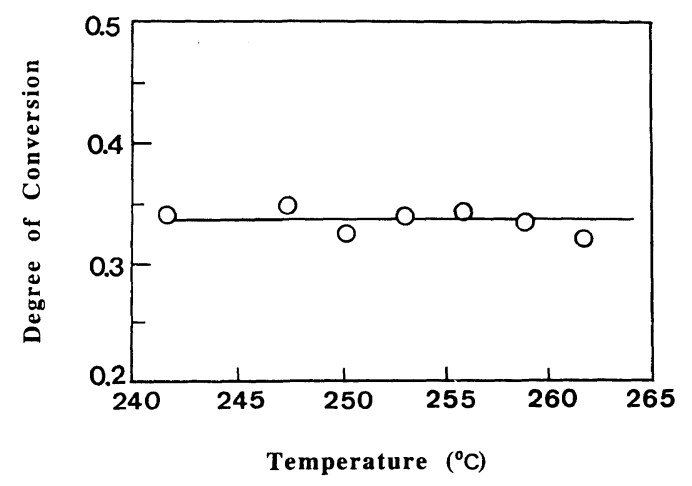

Figure 5. Degree of conversion at peak as a function of cure temperature.

overall reaction order $(m+n)$ for the epoxyamine system was second. Based on this assumption, the following equation was used in this study.

$$
m=\frac{\ln \left(\frac{\left(\dot{\alpha}_{\mathrm{p}} /\left(1-\alpha_{\mathrm{p}}\right)^{2-m}-k_{1}\right)}{(2-m) k_{1} \alpha_{\mathrm{p}}{ }^{1-m} /\left(m-2 \alpha_{\mathrm{p}}\right)}\right)}{\ln \alpha_{\mathrm{p}}}
$$

The quantities $k_{1}, \dot{\alpha}_{\mathrm{p}}$, and $\alpha_{\mathrm{p}}$ are directly determined at any given temperature using DSC. A cure study of TGDDM/DDS system with kinetic model (eq 1) has been recently reported by Barton. ${ }^{29} \mathrm{He}$ has mentioned that reaction up to about $20-30 \%$ conversion 


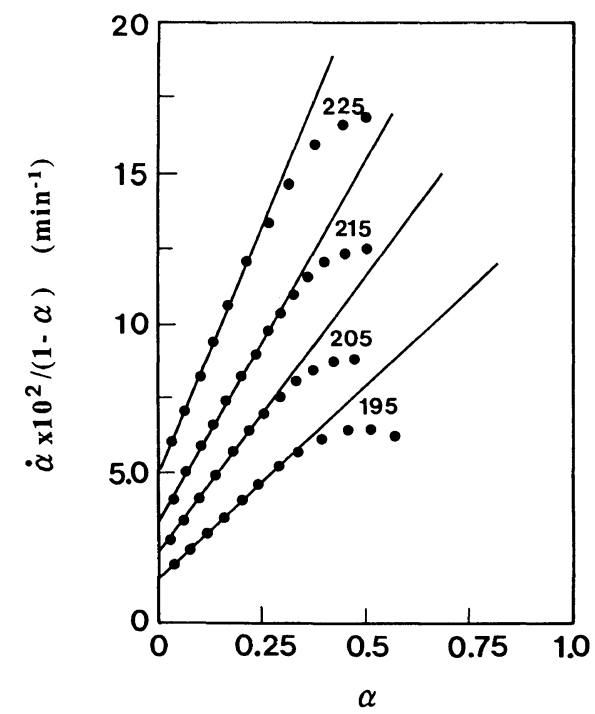

Figure 6. $\alpha /(1-\alpha)^{n}$ versus $\alpha^{m}$ in the case of $m=n=1$. The numbers in the figure indicate cure temperatures.

provides linear plots based on the assumption of $m=n=1$. The plot of $\dot{\alpha} /(1-\alpha)^{n}$ against $\alpha^{m}$ for $m=n=1$ is illustrated in Figure 6. From this manipulation of autocatalytic kinetic model, the early stage of reaction provides linear relationship up to approximately $35 \%$ conversion. The experimental results at higher conversion show slow rates than the theoretical prediction. On the other hand, kinetic parameter $m$ was calculated from eq 1 numerically by means of a Newton-Raphson technique. ${ }^{26}$ By using the obtained parameters, $k_{2}$ value can be determined from the slope of $\dot{\alpha} /(1-\alpha)^{n}$ against $\alpha^{m}$ (Method 1).

Figure 7 shows $\dot{\alpha} /(1-\alpha)^{n}$ as a function of $\alpha^{m}$ with $m$ values obtained from eq 1 . Linearity of these plots indicates a good fitting with experimental results and the data obey the model up to approximately $50 \%$ conversion. Compared to the assumption of $m=n=1$, this modified manipulation of the autocatalytic model would be more adequate for tetrafunctional epoxy-amine system. The activation energy $\left(E_{\mathbf{a}_{2}}\right)$ and $k_{2}$ for formulation $\mathrm{HH} 1$ are given in Table II.

The other method was introduced for

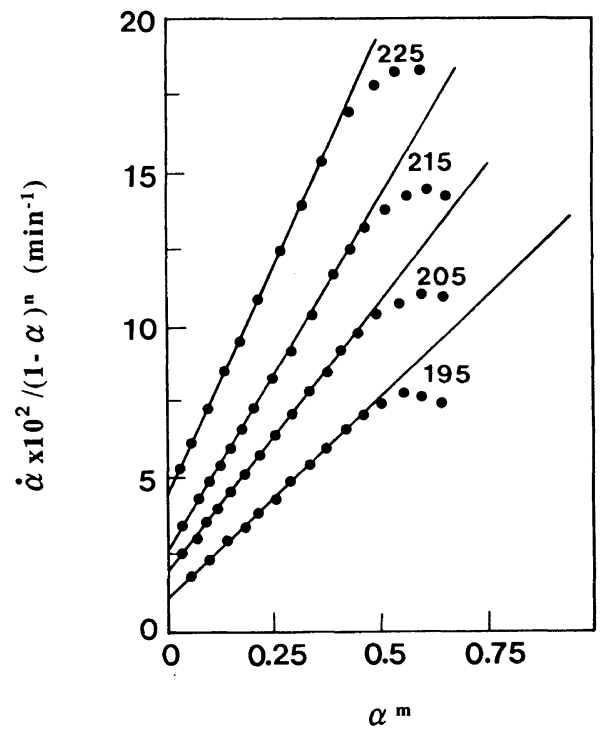

Figure 7. $\alpha /(1-\alpha)^{n}$ versus $\alpha^{m}$ by using kinetic parameter in obtained from the peak constant. The numbers in the figure indicate cure temperatures.

Table II. Physical properties of DAP curing agent

$\begin{array}{lc}\text { Physical form } & \text { Crystalline solid } \\ \text { Color } & \text { Tan to cream } \\ \begin{array}{l}\text { Melting point } \\ \text { Approximately equivalent } \\ \text { weight/active hydrogen }\end{array} & 861-154^{\circ} \mathrm{C} \\ \end{array}$

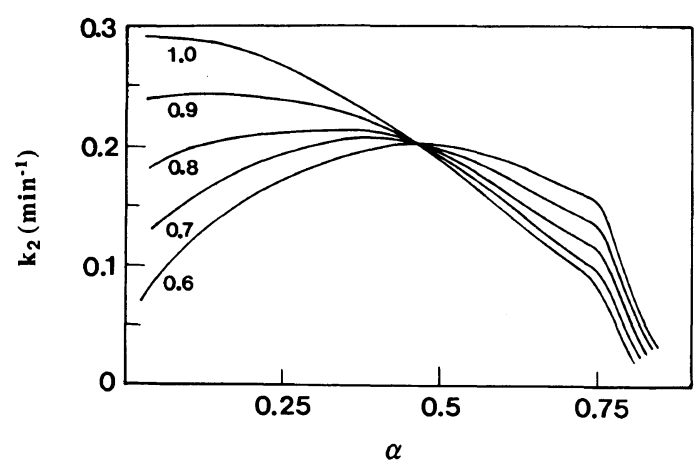

Figure 8. Cure rate constant $\left(k_{2}\right)$ as a function of conversion $(\alpha)$ with various $m$ values.

determining $k_{2}$ and $m$ values. Substituting arbitrary values of $m$ and $n=2-m, k_{2}$ value can be directly obtained from the autocatalytic kinetic equation. When $k_{2}$ value against the 
DSC Cure Studies of High Performance Epoxy Resins. II

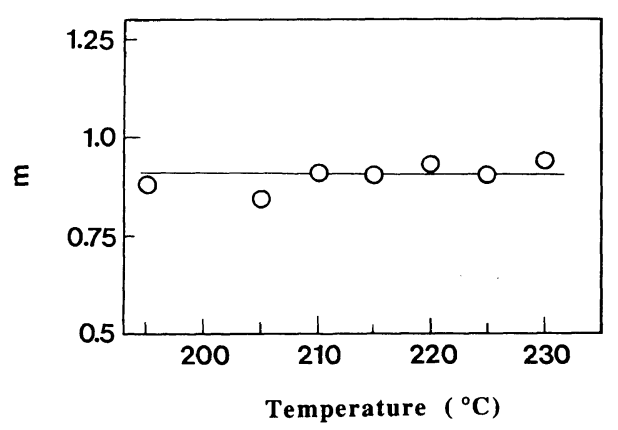

Figure 9. Kinetic parameter $m$ as a function of cure temperature.

degree of cure is constant, $m$ and $k_{2}$ value would be determined automatically (Method II).

Figure 8 demonstrates $k_{2}$ value against the degree of cure at $215^{\circ} \mathrm{C}$ for $\mathrm{HH} 1$. The $k_{2}$ values are nearly constant in the range of $0.85-0.95$ values of $m$. The temperature dependence of $m$ value is shown in Figure 9. For a constant formulation, the value of $m$ was independent of cure temperature. Values of $m$ mostly remain between 0.85 and 0.95 .

A summary of corresponding kinetic parameters is given in Table III. The activation energy calculated from both means is nearly similar. Reasonably good agreement can be obtained between these two methods.

\section{REFERENCES}

1. A. Apicella, L. Nicolais, G. Astarita, and E. Drioli, Polymer, 2(9), 1143 (1979).

2. E. T. Mones and R. J. Morgan, Polym. Prepr., Am. Chem. Soc. Div. Polym. Chem., 22, 249 (1981).

3. C. A. May, M. R. Dusi, J. S. Fritzen, D. K. Hadad, M. G. Maximovich, and K. S. Thrasher., Am. Chem. Soc. Org. Coat. Appl. Polym. Sci. Proc., 47, 419 (1982).

4. W. X. Zukas, W. J. MacKnight, and N. S. Schneider, Am. Chem. Soc. Org. Coat. Appl. Polym. Sci. Proc., 47, 425 (1982).

5. G. L. Hagnauer, P. J. Pearce, B. R. LaLiberte, and M. E. Roylance, Am. Chem. Soc. Org. Coat. Appl. Polym. Sci. Proc., 47, 429 (1982).

6. J. Moacanin, M. Cizmecioglu, F. Tsay, and A. Gupta, Am. Chem. Soc. Org. Coat. Appl. Polym. Sci. Proc., 47, 587 (1982).

7. E. T. Mones, C. M. Walkup, J. A. Happe, and R. J.
Table III. Summary of kinetic parameters for $\mathrm{HH} 1$

$$
\begin{aligned}
& \text { Method I } \\
& \begin{array}{ll}
k_{1} \quad 2.43 \times 10^{4} \mathrm{exp}\left(-\frac{-9.29 \times 10^{4} \mathrm{Jg}^{-1} \mathrm{~mol}^{-1}}{R T}\right) \\
k_{2} \quad 1.38 \times 10^{5} \mathrm{exp}\left(-\frac{5.42 \times 10^{4} \mathrm{Jg}^{-1} \mathrm{~mol}^{-1}}{R T}\right) \\
E_{\mathrm{a}_{2}}\left(\mathrm{~kJ} \mathrm{~g}^{-1} \mathrm{~mol}^{-1}\right)
\end{array}
\end{aligned}
$$

Method II

$$
\begin{aligned}
& k_{2} \quad 1.23 \times 10^{5} \exp \left(-\frac{5.35 \times 10^{4} \mathrm{Jg}^{-1} \mathrm{~mol}^{-1}}{R T}\right) \\
& E_{\mathrm{a}_{2}}\left(\mathrm{~kJ} \mathrm{~g}^{-1} \mathrm{~mol}^{-1}\right)
\end{aligned}
$$

Morgan, Proceedings of the 14th National SAMPE Technical Conference, Atlanta, GA., October 1982, pp 89-100.

8. R. J. Morgan, J. A. Happe, and E. T. Mones, paper presented at the 28th National SAMPE Symposium, Anaheim, Calif., April 12-14, 1983.

9. J. Mijovic, J. Kim, and J. Slaby, J. Appl. Polym. Sci., 29, 1449 (1984).

10. J. Mijovic, J. Appl. Polym. Sci., 31, 1177 (1986).

11. M. H. Clancy and D. E. Luft, The Proceedings of 18th International SAMPE Technical Conference, 135-141, October 7-9, 1986.

12. C. E. Browning, Polym. Eng. Sci., 18, 16 (1978).

13. E. L. McKague, J. D. Reynold, and J. E. Haskin, J. Appl. Polym. Sci., 22, 1643 (1978).

14. R. S. Bauer, A. G. Filippov, L. M. Schlaudt, and W. V. Breitigam, The Proceedings of 32nd International SAMPE Symposium, April 6-9, 1987, pp 1105-1 113.

15. R. S. Bauer, A. G. Filippov, L. M. Schlaudt, and W. V. Breitigam, The Proceedings of 33rd International SAMPE Symposium, March 7-10, 1988, pp 13851393.

16. R. S. Bauer, The Proceedings of 34th International SAMPE Symposium, May 8-11, 1989, pp 1889-1900.

17. L. M. Schlaudt, R. S. Bauer, and C. A. Blackburn, The Proceedings of 34th International SAMPE Symposium, May 8-11, 1989, pp 917-928.

18. R. A. Fava, Polymer, 9, 137 (1968).

19. K. Horie, H. Hiura, M. Sawada, I. Mita, and H. Kambe, J. Polym. Sci., 8, 1357 (1970).

20. M. A. Acitelli, R. B. Prime, and E. Sacher, Polymer, 12, 333 (1971).

21. M. R. Kamal and S. Sourour, Polym. Eng. Sci., 13(1), 59 (1973).

22. R. B. Prime and E. Sacher, Polymer, 13, 455(1972).

23. R. B. Prime, "Thermal Characterization of Polymeric Materials", Chap. 5, Academic Press, Inc., New York, 1984.

24. C. C. Riccardi, H. E. Adabbo, and R. J. Williams, 
J. Appl. Polym. Sci., 29, 2481 (1984).

25. R. B. Prime, Polym. Eng. Sci., 13(5), 365 (1973).

26. M. E. Ryan and A. Dutta, Polymer, 20, 203 (1979).

27. T. Provder, R. M. Holsworth, T. H. Grentzer, and

S. A. Kline, "Polymer Characterization", American
Chemical Society, Washington, D. C., 1983, Chapter 13.

28. J. S. Shim, W. Lee and J. S. Jang, Submitted to Polym. Bull. (1990).

29. J. M. Barbon, Br. Polym., 18, 37 (1986). 